\title{
GUANETHIDINE-INDUCED DESTRUCTION OF PERIPHERAL SYMPATHETIC NEURONS OCCURS BY AN IMMUNE-MEDIATED MECHANISM $^{1}$
}

\author{
PAMELA TOY MANNING, ${ }^{2}$ CHRISTINE W. POWERS, ROBERT E. SCHMIDT, ${ }^{*}$ AND \\ EUGENE M. JOHNSON, JR.
}

Departments of Pharmacology and ${ }^{*}$ Pathology, Washington University School of Medicine, St. Louis, Missouri 63110

Received August 3, 1982; Revised November 2, 1982; Accepted November 11, 1982

\begin{abstract}
Guanethidine, a guanidinium adrenergic neuron blocking agent, when administered chronically at high doses to newborn or adult rats, causes destruction of peripheral sympathetic neurons. Neuronal destruction is preceded by small cell infiltration of the sympathetic ganglia and is suggestive of an immunologically mediated mechanism. Immune reconstitution experiments were carried out to demonstrate that guanethidine-induced neuronal destruction occurs by an immunologically mediated mechanism. To determine the dose of irradiation necessary to protect against neuronal cell death induced by guanethidine, 3-week-old Lewis rats were treated with either 600,750 , or 900 rads of $\gamma$-irradiation $6 \mathrm{hr}$ prior to the initiation of guanethidine treatment. Rats received $50 \mathrm{mg} / \mathrm{kg}$ of guanethidine sulfate for 5 days, were killed 2 days later, and the superior cervical ganglia were dissected for assay of tyrosine hydroxylase activity and for light microscopic evaluation. Irradiation protected against guanethidine-induced destruction in a dose-related manner, with virtually complete protection afforded by doses of 900 rads. Adoptive transfer recipients were irradiated with 850 rads immediately prior to cell transfer. Adoptive transfer experiments involved four groups of animals: group A (guanethidine only); group B (irradiated only); group C (irradiated + guanethidine); and group D (irradiated + guanethidine + syngeneic spleen and bone marrow cells). By light microscopic examination, sympathetic ganglia from animals in groups $\mathrm{B}$ and $\mathrm{C}$ were normal, whereas ganglia from animals in group A showed the usual marked small cell infiltration and neuronal destruction. Animals in group $\mathrm{D}$, in contrast to group $\mathrm{C}$, showed clear small cell infiltration of the ganglia and neuronal destruction. In addition, tyrosine hydroxylase activity was significantly reduced in group D compared to groups B and C. By ultrastructural analysis, the cellular infiltrate within the ganglia of guanethidine-treated rats consists of small lymphocytes, activated lymphocytes, macrophages, and polymorphonuclear leukocytes. T lymphocytes, responsible largely for cell-mediated immune responses, were identified immunohistochemically within ganglia of treated animals. These results indicate that the small cell infiltration and neuronal destruction due to guanethidine treatment involve an immune-mediated component.
\end{abstract}

Guanethidine is a guanidinium adrenergic neuron blocking agent used clinically as an antihypertensive agent. The chronic administration of high doses of guanethidine to either newborn or adult rats, but not to other species, causes destruction of peripheral sympathetic neurons (i.e., sympathectomy). The specificity for

\footnotetext{
${ }^{1}$ Part of the results were presented in abstract form at the annual meeting of the Society for Neuroscience, October 1981. This work was supported by National Institutes of Health Grants HL-20604 and AM19645 and Cardiovascular Training Grant 5-T32-HL-07275. P. T. M. is an American Heart Association, Missouri, Affiliate Fellow. E. M. J. is an Established Investigator of the American Heart Association.

${ }^{2}$ To whom correspondence should be addressed.
}

destruction of sympathetic neurons seems to be due to the selective accumulation of guanethidine within this cell type. Guanethidine does not accumulate in other cell types (i.e., sensory neurons) nor does it cause their destruction (Burnstock et al., 1971; Eränkö and Eränkö, 1971; Jensen-Holm and Juul, 1971).

Several mechanisms have been proposed to account for the cytotoxic effects of guanethidine, including the inhibition of oxidative phosphorylation (Heath et al., 1972; Johnson and Aloe, 1974), the inhibition of the retrograde transport of nerve growth factor (NGF) (Johnson, 1978), and the inhibition of polyamine biosynthesis (Johnson and Taylor, 1980). However, none of these explanations seems to be responsible for the neu- 
ronal destruction induced by guanethidine (Johnson and Hunter, 1979; Johnson et al., 1979; Johnson and Taylor, 1980). The cytotoxic effect is associated with a marked infiltration of small cells into the ganglion, presumably lymphocytic (Eränkö and Eränkö, 1971; Jensen-Holm and Juul, 1971). The small cell infiltration seems to precede the neuronal cell death (Manning et al., 1982). This and several other observations in the literature (Eränkö et al., 1972; Johnson and Aloe, 1974; Evans et al., 1975; Révész and van der Zypen, 1979) suggested for rcasons we have previously described (Manning et al., 1982 ) that guanethidine may exert its cytotoxic effects by an immunologically mediated mechanism. Indeed, this type of mechanism was suggested in the early paper of Jensen-Holm and Juul (1971). In support of this hypothesis, we have recently shown that the administration of various immunosuppressive agents, including cyclophosphamide, $\gamma$-irradiation, azathioprine, and dexamethasone, partially or completely prevented guanethidineinduced neuronal destruction. The protection afforded by these immunosuppressive agents was not due to a failure of guanethidine to accumulate within the ganglia, nor did these agents protect against the sympathectomy produced by administration of either 6-hydroxydopamine (6-OIIDA) or antibodies to NGF (Manning et al., 1982), both of which destroy sympathetic neurons without eliciting an immune response in the treated animal (LeviMontalcini and Angeletti, 1966; Angeletti and Levi-Montalcini, 1970).

To demonstrate that guanethidine-induced destruction occurs by an immunologically mediated mechanism, adoptive transfer experiments were carried out. Immune competent spleen and bone marrow cells obtained from syngeneic, normal rats were transferred to lethally irradiated recipients. The lethally irradiated rats were then treated with guanethidine to determine whether immune reconstitution restored sensitivity to guanethidine-induced sympathectomy. This type of protocol has classically been used to establish an immune mechanism as the basis for various phenomena (Paterson, 1960; Abramson et al., 1977; Ertl, 1981). In addition, the small cells which accumulate within the ganglia following guanethidine treatment were characterized using ultrastructural and immunohistochemical techniques.

\section{Materials and Methods}

\section{Animal treatments}

Adoptive transfer experiments. To determine the amount of irradiation necessary to provide maximal protection against guanethidine-induced neuronal destruction, 3-week-old, male Lewis rats (M.A. Bioproducts, Walkersville, MD) were treated with either 600,750 , or 900 rads of $\gamma$-irradiation (Gamma Cell 40, Atomic Energy of Canada). Three-week-old animals were the youngest which we were able to inject with sufficient volumes of cell suspensions. Animals were irradiated $6 \mathrm{hr}$ prior to the initiation of guanethidine treatment, as the most effective immunosuppressive effects of irradiation have previously been shown to occur when irradiation precedes or coincides with antigen administration (Kohn, 1951). Rats received $50 \mathrm{mg} / \mathrm{kg}$ of guanethidine sulfate (Ciba-Geigy Corp., Summit, NJ) intraperitoneally for 5 days, were killed 2 days later, and the superior cervical ganglia (SCGs) were quickly dissected for assay of tyrosine hydroxylase (TOH) activity and for histological evaluation. The controls for the guanethidine alone group (no irradiation) were untreated. For each dose of irradiation, there was a control group that received the indicated amount of radiation but no guanethidine (irradiated control groups).

Adoptive transfer experiments involved four groups of animals: group A-guanethidine only, no irradiation; group $\mathrm{B}$-irradiatcd only; group $\mathrm{C}$-irradiated + guanethidine; and group D-irradiated + spleen and bone marrow cells + guanethidine. In two separate experiments, 3-week-old, male Lewis rats (groups B, C, and D) were treated with 850 rads of $\gamma$-irradiation immediately prior to the initial cell transfer. Cells were transferred on 2 successive days, because recipients, presumably due to their size ( 60 to $80 \mathrm{gm}$ at 3 weeks of age), were found not to tolerate intravenous injections of large numbers of cells at one time. On day 1 recipients (group D) received a combination of $3 \times 10^{8}$ (experiment I) or $6 \times 10^{8}$ (in two injections, $2 \mathrm{hr}$ apart, experiment II) bone marrow and spleen cells intravenously which were obtained from adult, syngeneic, untreated donors as described below. Twenty-four hours later (day 2), recipients also received $2 \times 10^{8}$ syngeneic spleen cells (experiment $\mathrm{I}$ ) or $7 \times 10^{8}$ spleen cells and bone marrow cells (in two injections, 2 hr apart, experiment II) intravenously (Fig. 1). All groups except the irradiated control (group B) received daily injections of $50 \mathrm{mg} / \mathrm{kg}$ of guanethidine sulfate intraperitoneally for 8 days. All animals were given solutions of

\section{RECONSTITUTION EXPERIMENTS}

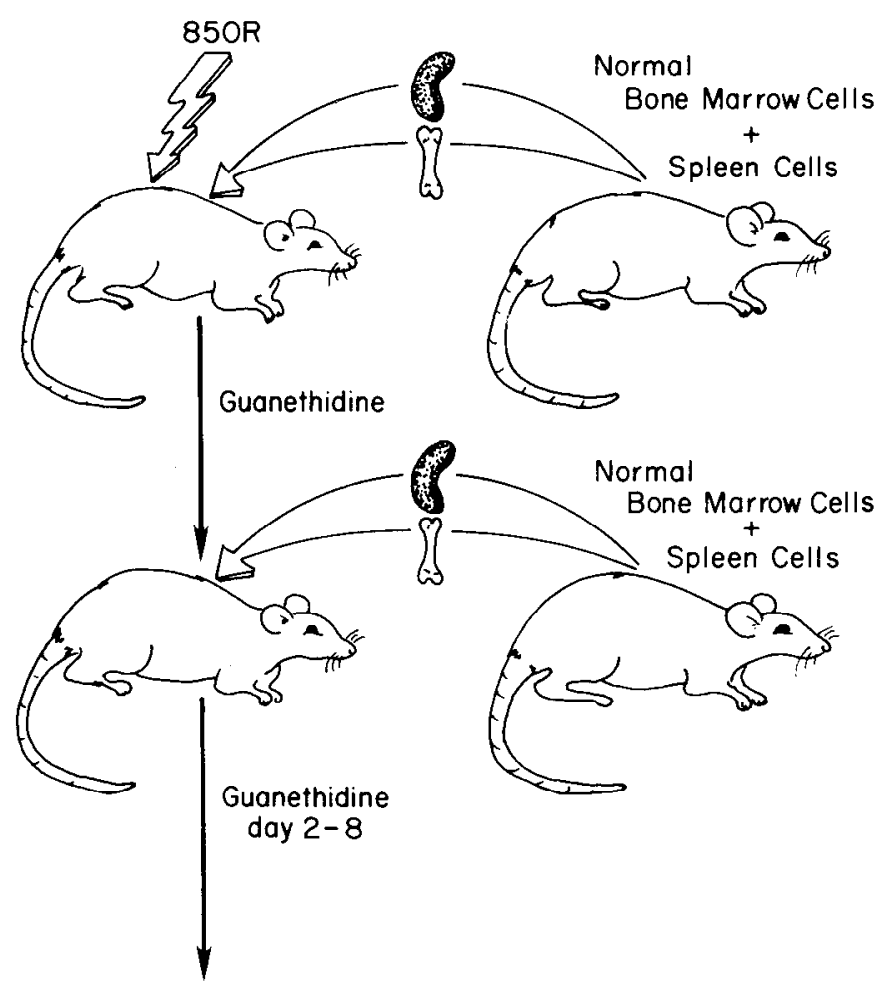

Killed day 9 or 10 for histology and TOH assay

Figure 1. Schematic of immune reconstitution experiments. 
$5 \%$ glucose rather than drinking water to encourage fluid consumption and to counteract the weight loss and dehydration resulting from the toxic effects of high dose irradiation on the gastrointestinal tract. Animals were killed on day 9 or 10, and the SCGs were quickly dissected for assay of TOH activity and for histological evaluation.

Identification of cellular infiltrate. To determine the nature of the small cell infiltrate, 7-day-old SpragueDawley rats (Chappel Breeders, St. Louis, MO) were treated with $50 \mathrm{mg} / \mathrm{kg}$ of guanethidine sulfate subcutancously for 5 days and were killed 2 days following the last injection for ultrastructural or immunohistochemical evaluation (see below).

\section{Cell preparation}

Spleen cells and bone marrow cells were prepared according to standard methods (Ford, 1978). Briefly, spleens were excised from normal adult Lewis rats, placed in Roswell Park Memorial Institute (RPMI) 1640 medium (KC Biologicals, Kansas City, MO), pH 7.2, containing $20 \mathrm{~mm}$ HEPES and $10 \%$ newborn bovine serum, and minced finely with scissors. Tissue fragments were allowed to settle. Spleen cells were then harvested from the supernatant fraction and from two successive washes of the tissue pellet, filtered through gauze, and centrifuged at $500 \times \mathrm{g}$ for $15 \mathrm{~min}$ at $4^{\circ} \mathrm{C}$. Cells were washed twice with medium, resuspended in a known volume, and counted using a hemocytometer. Viability was assessed using trypan blue exclusion. Bone marrow cells were obtained from the femurs of the same rats, filtered through gauze, washed twice in medium, and counted as described for spleen cells. Spleen and bone marrow cells were then combined, centrifuged, and resuspended in a known volume of medium such that each recipient received the appropriate number of cells in a volume of 0.5 $\mathrm{ml}$.

\section{Tyrosine hydroxylase activity}

Superior cervical ganglia were homogenized at 0 to $4^{\circ} \mathrm{C}$ in $5 \mathrm{~mm}$ Tris buffer, $\mathrm{pH} 7.4$, containing $0.2 \%$ Triton $\mathrm{X}-100$, at a dilution that assured that the reaction was linear with enzyme concentration and time. Tyrosine hydroxylase (EC 1.14.16.2) activity was measured by a modification of the method of Nagatsu et al. (1964) in the presence of $40 \mu \mathrm{M}$ tyrosine $(0.1 \mu \mathrm{Ci} \mathrm{L-}$ [side chain$2,3-{ }^{3} \mathrm{H}$ tyrosine; Amersham, Arlington Heights, IL) and $825 \mu \mathrm{M}$ 6-methyl-5,6,7,8-tetrahydropterine dihydrochloride. The $\left[{ }^{3} \mathrm{II}\right] \mathrm{DOPA}$ formed was adsorbed onto alumina at $\mathrm{pH} 8.2$ to 8.4 , eluted with $2 \mathrm{ml}$ of $0.1 \mathrm{~N} \mathrm{HCl}$, and assayed for radioactivity.

\section{Histological analysis}

SCGs were quickly dissected and fixed by immersion in $10 \%$ formalin/saline. Following dehydration of fixed tissue in graded ethanol solutions, the tissue was embedded in paraffin, cut in $7-\mu \mathrm{m}$ sections, rehydrated, and stained with toluidine blue.

\section{Immunohistochemistry}

Surface antigens of rat $\mathrm{T}$ lymphocytes were identified by indirect immunohistochemical methods using a rabbit anti-rat $\mathrm{T}$ lymphocyte primary antibody (see below) and a peroxidase-labeled secondary antibody (anti-rabbitIgG). Tissues were quickly excised, frozen, and mounted. Due to the small size of the SCG, it was placed between two pieces of skclctal muscle for support and then frozen immediately. This allowed more reproducible sectioning. Cryostat sections, $10 \mu \mathrm{M}$, were cut, air dried on glass slides, and fixed in cold $100 \%$ ethanol for $5 \mathrm{~min}$. Tissue sections were pre-incubated for $30 \mathrm{~min}$ each in methanol followed by $0.03 \%$ hydrogen peroxide to reduce endogenous peroxidase activity and in a $5 \%$ solution of normal goat serum to reduce nonspecific binding. Sections were then incubated overnight at $4^{\circ} \mathrm{C}$ with a 1:50 dilution of either normal rabbit serum (NRS) or rabbit anti-rat $\mathrm{T}$ cell serum (ATS) in phosphate-buffered saline (PBS) containing $5 \%$ normal goat serum. Anti-rat $\mathrm{T}$ cell serum was prepared essentially as described by Ishii et al. (1975). Briefly, $1 \times 10^{7} \mathrm{~T}$ lymphocytes, obtained from rat mesenteric lymph nodes and enriched on nylon wool (Julius et al., 1973), were injected intravenously into a rabbit, which was subsequently boosted at monthly intervals with $2 \times 10^{7} \mathrm{~T}$ cells, subcutaneously. Both the NRS and ATS were extensively adsorbed with rat liver and skeletal muscle to eliminate nonspecific binding to rat tissue and to enhance specificity of the antiserum for rat $T$ lymphocytes (Kaplan, 1958). After washing three times each for $15 \mathrm{~min}$ in PBS, tissues were then incubated with peroxidase-conjugated goat anti-rabbit IgG (Cappel Laboratories, Cochranville, PA) overnight at $4^{\circ} \mathrm{C}(1: 200$ dilution in PBS containing 5\% normal goat serum). Tissues were stained using diaminobenzidine (DAB) as described by Adams (1981). The slides were washed in PBS, dehydrated through a series of graded ethanol solutions, and permanently mounted.

\section{Ultrastructural methods}

Superior cervical ganglia were dissected quickly and fixed by immersion in $3 \%$ glutaraldehyde in $100 \mathrm{~mm}$ phosphate buffer, pH 7.3, containing $0.45 \mathrm{~mm} \mathrm{Ca}^{++}$. Subsequently, tissues were postfixed in buffered $\mathrm{OsO}_{4}$, dehydrated in graded alcohols, and embedded in Epon/ Araldite or Spurr's medium. Semithick sections were examined by light microscopy after staining with toluidine blue. Thin sections were stained with uranyl acetate and lead citrate and were examined with a Philips 200 electron microscope.

\section{Results}

\section{Adoptive transfer experiments}

To determine the dose of irradiation necessary to protect against guanethidine-induced neuronal cell death, 3-week-old Lewis rats were treated with either 600,750 , or 900 rads of $\gamma$-irradiation $6 \mathrm{hr}$ prior to the initiation of guanethidine treatment. Rats then received $50 \mathrm{mg} / \mathrm{kg}$ of guanethidine sulfate for 5 days and were killed 2 days later and evaluated for neuronal destruction as described under "Materials and Methods." As had been previously seen in younger, outbred Sprague-Dawley rats (Manning et al., 1982), irradiation protected against guanethidine-induced decreases in TOH activity and against histological changes in a dose-dependent manner (Table I). Guanethidine treatment alone (no irradiation) caused a $55 \%$ decrease in $\mathrm{TOH}$ activity as 
TABLE I

Effects of various amounts of $\gamma$-irradiation on guanethidine-induced reduction in tyrosine hydroxylase (TOH) activity in sympathetic neurons

\begin{tabular}{lcc}
\hline \multicolumn{1}{c}{ Treatment $^{\alpha}$} & $\begin{array}{c}\text { Tyrosine Hydroxylase } \\
\text { Activity } \\
\text { (nmoles Tyrosine } \\
\text { Oxidized/SCG/hr) }\end{array}$ & $\begin{array}{c}\text { \% Control } \\
\text { (TOH } \\
\text { Activity) }\end{array}$ \\
\hline Control & $3.64 \pm 0.29(5)^{c}$ & \\
Guanethidine & $1.62 \pm 0.08(5)^{d}$ & 45 \\
600 rads & $4.44 \pm 0.31(5)$ & 60 \\
600 rads + guanethidine & $2.67 \pm 0.20(5)^{d}$ & \\
750 rads & $3.88 \pm 0.27(7)$ & 62 \\
750 rads + guanethidine & $2.39 \pm 0.11(7)^{d}$ & \\
$900 \mathrm{rads}^{e}$ & & \\
$900 \mathrm{rads}+$ guanethidine & $3.96 \pm 0.20(7)$ & 89 \\
\hline
\end{tabular}

"Six hours prior to the initiation of guanethidine treatment, 3 -weekold Lewis rats were treated once with 600,750 , or 900 rads of $\gamma$ irradiation. Rats received $50 \mathrm{mg} / \mathrm{kg}$ of guanethidine sulfate for 5 days and were killed 2 days later, and the superior cervical ganglia were dissected for assay of $\mathrm{TOH}$ activity and for histological evaluation. The control group for the guanethidine alone group (no irradiation) was untreated. There were also control groups which received the indicated amount of radiation, but no guanethidine.

${ }^{b}$ Percentage of appropriate non-guanethidine-treated control.

"Numbers represent the mean \pm SEM for $(n)$ animals.

${ }^{d}$ Differs from respective control at $p<0.001$ level of significance by the Student's $t$ test for independent groups.

'In the groups which received 900 rads and $900 \mathrm{rads}+$ guanethidine, $22 \%$ and $60 \%$ mortality occurred, respectively. No deaths occurred in any other group.

compared to untreated control values. Histologically, ganglia from animals treated with guanethidine alone exhibited areas of marked cell infiltration and evidence of neuronal damage including the presence of many neurons with pale-staining cytoplasm resulting in the apparent death of neurons as evidenced by a decrease in cell density (cell counts not done; see Fig. $2 A$ ). The decrease in $\mathrm{TOH}$ activity and the degenerative histological changes resulting from guanethidine treatment alone were less dramatic than that which occurs following the same treatment of a 1-week-old rat (85 to $90 \%$ decrease; Manning et al., 1982). Treatment with 600 and 750 rads of $\gamma$-irradiation and guanethidine provided partial protection against guanethidine-induced reduction in $\mathrm{TOH}$ activity. TOH activity was reduced only by approximately $40 \%$ following treatment with either 600 or 750 rads of irradiation + guanethidine as compared to the appropriate irradiated control group. In addition, histological changes were less dramatic, although still readily apparent (photomicrographs not shown). Essentially complete protection was afforded by doses of 900 rads of irradiation. TOH activity was not reduced significantly compared to control $(p>0.25)$ and ganglia appeared virtually normal by light microscopy (photomicrographs not shown). However, significant mortality occurred in the groups that received either 900 rads of irradiation alone or 900 rads and guanethidine treatment $(22 \%$ and $60 \%$, respectively). The dose of irradiation was, therefore, reduced to 850 rads in the reconstitution experiments.
The degree of mortality was less with no apparent loss in protection measured by TOH activity (Table III).

Adoptive transfer experiments were done to demonstrate that guancthidine-induced destruction occurs by an immunologically mediated mechanism. In two separate experiments, normal, syngeneic spleen and bone marrow (immune competent) cells were transferred intravenously to lethally irradiated recipients on 2 consecutive days (see Fig. 1 and Table II for details). 'The capacity of these recipients to regain sensitivity to guanethidine-induced neuronal destruction following a series of eight daily injections $(50 \mathrm{mg} / \mathrm{kg}$ /day) was assessed both morphologically and biochemically. Four groups of animals were included in these experiments: group Aguanethidine only, not irradiated; group B-irradiated only; group C-irradiated + guanethidine; and group Dirradiated + spleen and bone marrow cells + guanethidine. In both experiments, ganglia from animals which were irradiated only or which were irradiated and also received guanethidine (groups $\mathrm{B}$ and $\mathrm{C}$, respectively) were normal (Table II and Fig. 2, $B$ and $C$ ), whereas ganglia from all rats which received guanethidine alone (no irradiation; group A) showed the usual marked small cell infiltration, presence of ghost-like neurons, and neuronal destruction (Fig. 2A). Animals in group D (irradiated, guanethidine-treated, and reconstituted with immune competent cells), in contrast to group C (received the same drug treatment but did not receive cells), showed clear small cell infiltration of the ganglia and neuronal destruction (Fig. 2, $D$ to $F$ ). In addition, there was a significant reduction in TOH activity in the SCGs of animals which were irradiated, received immune competent cells, and were treated with guanethidine (group D) compared to animals which were irradiated and were treated with guanethidine but did not receive cells (group C; Table III). There was no significant difference in TOH activity between the irradiated control group (group B) and group $\mathrm{C}$, which was irradiated and treated with guanethidine, again demonstrating complete protection by irradiation. TOH activity in the ganglia of animals which received guanethidine only (group A) was also significantly reduced compared to control. The magnitude of this decline and the histological changes observed (Table III and Fig. 2) were, however, greater in the intact than in the immune-reconstituted animals. In addition, attempts to restore sensitivity to guanethidine in lethally irradiated recipients using serum from guanethidinetreated rats were unsuccessful (data not shown). These results demonstrate that following guanethidine treatment, the small cell infiltration, neuronal destruction, and reduction in $\mathrm{TOH}$ activity in sympathetic ganglia occur due to an immunologically mediated phenomenon and that the mechanism seems to be cellular rather than humoral.

\section{Identification of small cell infiltrate}

To further characterize the role of the immune system in guanethidine-induced neuronal destruction, the cellular infiltrate within the ganglia following guanethidine treatment was identified using immunohistochemical and ultrastructural methods.

Immunohistochemistry. Tissue specificity of the rabbit 

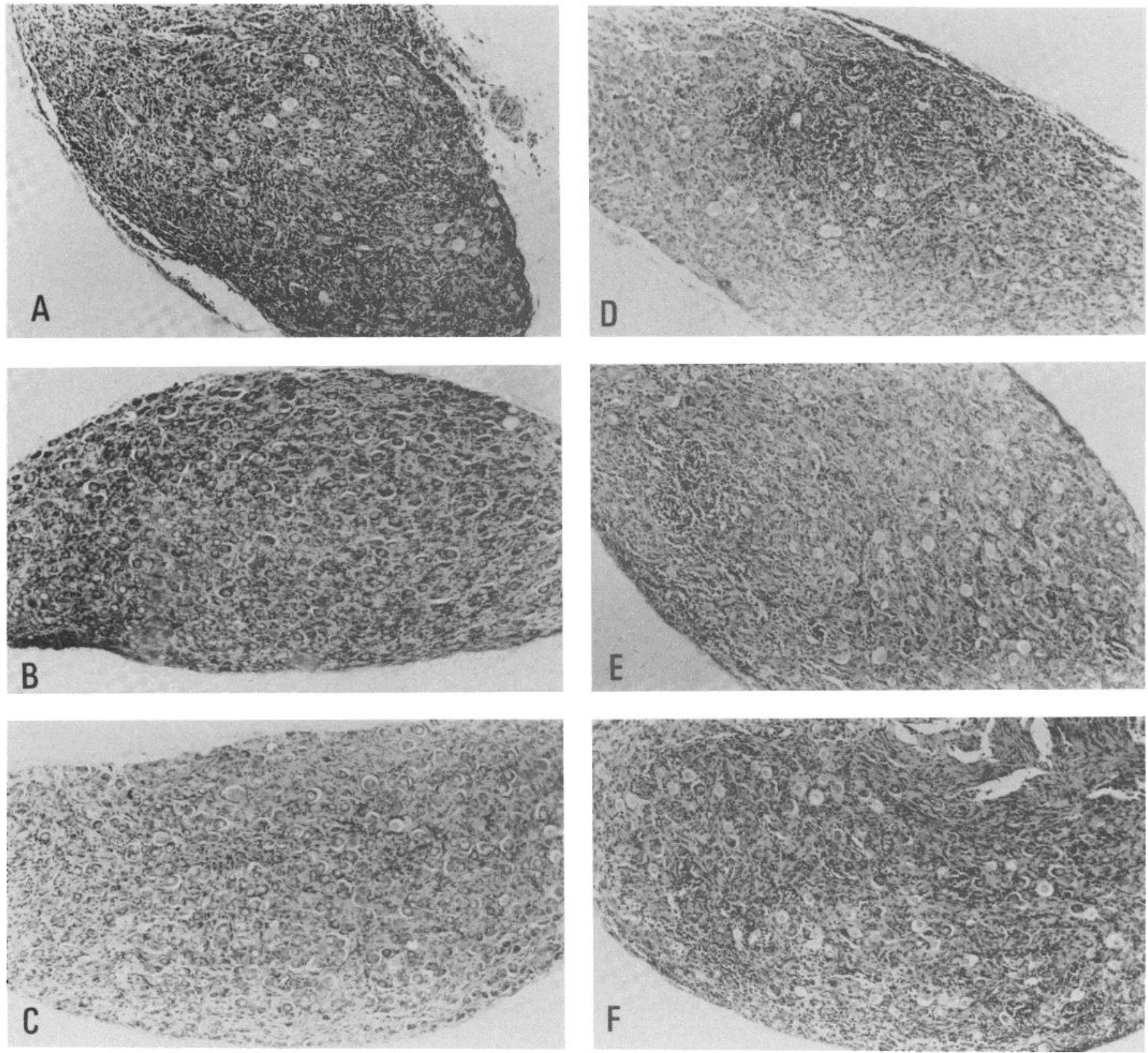

Figure 2. Histological changes in the SCG following immune reconstitution $A$, Not irradiated + guanethidine. $B$, Irradiated control. $C$, Irradiated + guanethidine. $D$ to $F$, irradiated + spleen and bone marrow cells + guanethidine, obtained from three different animals. Magnification $\times 63$.

anti-rat thymocyte serum for rat $\mathrm{T}$ cells was assessed by staining sections of various tissues (perfused with saline to remove blood and, thus, lymphoid cells), including rat liver, skeletal muscle, thymus, spleen, and kidney. With the exception of the two lymphoid organs, spleen and thymus, no specific staining, visualized using a peroxidase-labeled secondary antibody, occurred with either NRS or ATS. In contrast, the membranes of the majority of cells in the thymus stained with ATS but not with NRS (photomicrographs not shown). The pattern of staining of the thymus was consistent with that previously reported (Uede et al., 1981; Bukovsky et al., 1982). In the spleen, the areas around the central arterioles, in which $T$ lymphocytes are predominantly localized, stained heavily with ATS. T cells were identified by dark rings surrounding the cell membranes. Tissue surrounding the periarteriolar sheath, where B cells are localized, did stain with ATS (Fig. $3 B$ ). Background staining with NRS is shown in Figure $3 A$.

The light microscopic appearance of both normal and guanethidine-treated ganglia is shown in Figure 3, $G$ and $H$, respectively. Ganglia from control rats examined by light microscopy did not contain any observable small cell infiltrate but, rather, consisted of densely packed neurons and associated supporting cells. There was no specific staining with ATS in control ganglia (photomicrograph not shown). In contrast, there was marked small cell infiltration and a virtual absence of viable neurons in the ganglia from guanethidine-treated rats (Fig. $3 H$ ). Numerous cells which stained with ATS were scattered 
TABLE II

Dependence of guanethidine-induced destruction of sympathetic neurons on immune reconstitution

\begin{tabular}{lcc}
\hline \multicolumn{1}{c}{ Treatment" } & \multicolumn{2}{c}{$\begin{array}{c}\text { Effect } \\
\text { (No. Affected/ } \\
\text { Total No.) }\end{array}$} \\
\cline { 2 - 3 } & $\begin{array}{c}\text { Experi- } \\
\text { ment I }\end{array}$ & $\begin{array}{c}\text { Experi- } \\
\text { ment II }\end{array}$ \\
\hline A. Not irradiated + guanethidine & $5 / 5$ & $5 / 5$ \\
B. Irradiated control & $0 / 8$ & $0 / 5$ \\
C. Irradiated + guanethidine & $0 / 9$ & $0 / 6$ \\
D. Irradiated + spleen and bone marrow & $10 / 11$ & $4 / 4$ \\
$\quad$ cells + guanethidine & &
\end{tabular}

"Three-week-old male Lewis rats (groups B, C, and D) were treated with 850 rads of $\gamma$-irradiation using a Gamma-Cell 40 immediately prior to initial reconstitution. Initially (day 1), recipients (group D) received a combination of $3.1 \times 10^{8}$ (experiment I) or $6 \times 10^{8}$ (experiment II) bone marrow and spleen cells, intravenously, obtained from adult, syngeneic, naive donors. Twenty-four hours later (day 2), recipients also received $2 \times 10^{8}$ syngeneic spleen cells (experiment I) or $7 \times 10^{8}$ spleen cells and bone marrow cells (experiment II). All groups except the control group (B) received daily injections of $50 \mathrm{mg} / \mathrm{kg}$ of guanethidine sulfate for 8 days. Animals were killed on day 9 or 10 , and the superior cervical ganglia were quickly removed for assay of tyrosine hydroxylase activity and for histological evaluation

"Presence of obvious small cell infiltration and neuronal destruction. 'Scored blindly by a neuropathologist.

TABLE III

Effect of immune reconstitution on guanethidine-induced reduction of tyrosine hydroxylase activity in sympathetic neurons

\% Control Tyrosine Hydroxylase Treatment Activity

A. Not irradiated + guanethidine $45.5 \% \pm 4.9^{b, c, e}(9)$

B. Irradiated control $100 \% \pm 3.9(12)$

C. Irradiated + guanethidine

D. Irradiated + spleen and bone marrow cells + guanethidine

$88.9 \%+4.5(14)$

$74.8 \% \pm 3.2^{c, d, f}(15)$

"Rats were treated as described in the previous table. On day 9 or 10 , the superior cervical ganglia were quickly dissected for assay of tyrosine hydroxylase activity.

${ }^{b}$ Numbers represent the pooled data for experiments I and II and are expressed as a percentage of the irradiated control. Numbers in parentheses are the number of animals per treatment.

'Differs from group B (irradiated control) at $p<0.01$ level of significance by the Student's $t$ test.

"Differs from group C (irradiated + guanethidine) at $p<0.05$ level of significance.

${ }^{e}$ Differs from group C (irradiated + guanethidine) at $p<0.01$ level of significance.

${ }^{f}$ Differs from group A (not irradiated + guanethidine) at $p<0.01$.

throughout the ganglia (Fig. $3, D$ and $F$ ). However, as expected, the $\mathrm{T}$ cells thus identified do not constitute the entire mononuclear infiltrate which is present. Of notice is the similarity in the size $(\sim 7 \mu \mathrm{m})$ and staining properties of the positive cells in the spleen and in the ganglion (Fig. 3, $B$ and $F$, respectively). Clusters of T cells were also localized around blood vessels and the outer edges of the ganglia. The presence of T lymphocytes within the cellular infiltrate of a ganglion following guanethidine treatment further supports a role for a cell-mediated immune response in the neuronal destruction induced by guanethidine.
Electron microscopy. Ultrastructural studies were carried out to complement the immunohistochemical analysis and to further characterize the immune response in guanethidine-induced neuronal destruction. Several superior cervical ganglia from guanethidine-treated neonatal rats, sacrificed at 2 weeks of age after 5 days of guanethidine treatment (beginning at 1 week of age), and from age-matched controls were examined. Neuronal destruction was extensive in guanethidine-treated ganglia (Fig. 4B) compared to age-matched controls (Fig. $4 A$ ) which contained a normal complement of neurons. Although relatively few neurons remained intact in treated ganglia, residual Schwann cells and axons were present (Fig. $4 B$ ). The cellular infiltrate consisted of a number of different cell types including macrophages ( $M$; large mononuclear phagocytic cells containing numerous intracytoplasmic vacuoles which contain osmiophilic and other cellular debris), a few polymorphonuclear leukocytes, and mononuclear cells (arrows) having characteristics typical of small lymphocytes (small cells consisting largely of nucleus with little surrounding cytoplasm). There was considerable variability in the intensity of the inflammatory cell infiltrate. A portion of the inflammatory cell infiltrate in a severely involved ganglion is shown (Fig. 5A) surrounding an intraganglionic capillary. Many of the infiltrating cells are small lymphocytes $(L)$. Larger cells (arrows) contain large, somewhat irregular or indented nuclei, with a dispersed chromatin pattern and large amounts of dense cytoplasm, suggestive of activated lymphocytes. A single mononuclear cell $(M)$, can be seen interdigitating between two endothelial cells. A few cells (Fig. $5 B$, arrow) show increased amounts of dilated rough endoplasmic reticulum, which is characteristic of differentiation along plasma cell lines. Well developed plasma cells (antibody-secreting cells), however, were not prominent at this time.

\section{Discussion}

Guanethidine has been shown to accumulate to very high concentrations ( 0.5 to $1.0 \mathrm{~mm})$ in sympathetic neurons (Juul and Sand, 1973; Johnson and Hunter, 1979). Our general hypothesis of the mechanism of guanethidine-induced destruction is that guanethidine perturbs the cell in such a way that a moiety, presumably a protein or glycoprotein, which is not normally present on the surface of the plasma membrane is exposed. This molecule would presumably be recognized as foreign (antigenic) by the animal's immune system. Alternatively, guanethidine could itself bind, either covalently or noncovalently, to a neuronal membrane protein as a hapten to form an antigen. NGF may provide protection against guanethidine-induced cell death by one of three possible mechanisms. It may (1) prevent expression or recognition of the guanethidine-induced antigen; (2) produce immunosuppression of the animal, thus blocking proliferation of the immune response; or (3) block the killing mechanism or effector function even in the presence of antigen and activation of immune competent cells.

In support of this hypothesis, we have previously shown that various immunosuppressive agents protect against guanethidine-induced neuronal destruction in both a time-and dose-dependent fashion. This protection was not found to be due to a lack of accumulation of 

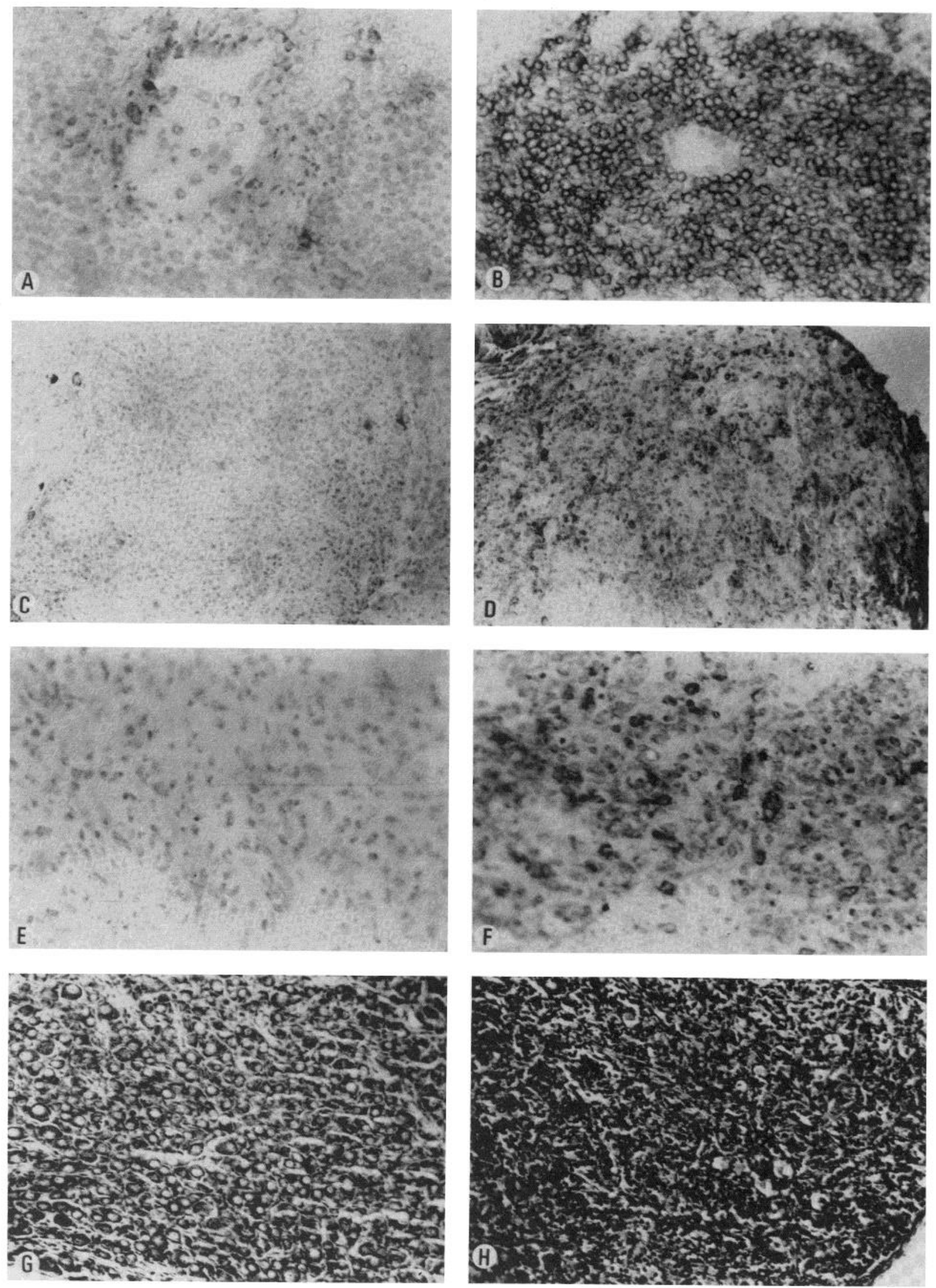

Figure 3. Identification of rat T cells by immunohistochemical staining. $A$, Spleen stained with NRS, $\times 250 . B$, Spleen stained with ATS, $\times 250$. Note the localization of densely packed lymphocytes around the central arteriole which can be identified by dark rings surrounding the cell membranes. $C$, Ganglion from guanethidine-treated rat stained with NRS, $\times 100$. $D$, Ganglion from guanethidine-treated rat stained with ATS, $\times 100$. Note T lymphocytes scattered throughout ganglion. $E$, Ganglion from guanethidine-treated rat stained with NRS, $\times 250$. F, Ganglion from guanethidine-treated rat stained with ATS, $\times 250$. G, Control ganglion, toluidine blue, $\times 100 . H$, Ganglion from guanethidine-treated rat, toluidine blue, $\times 100$. 

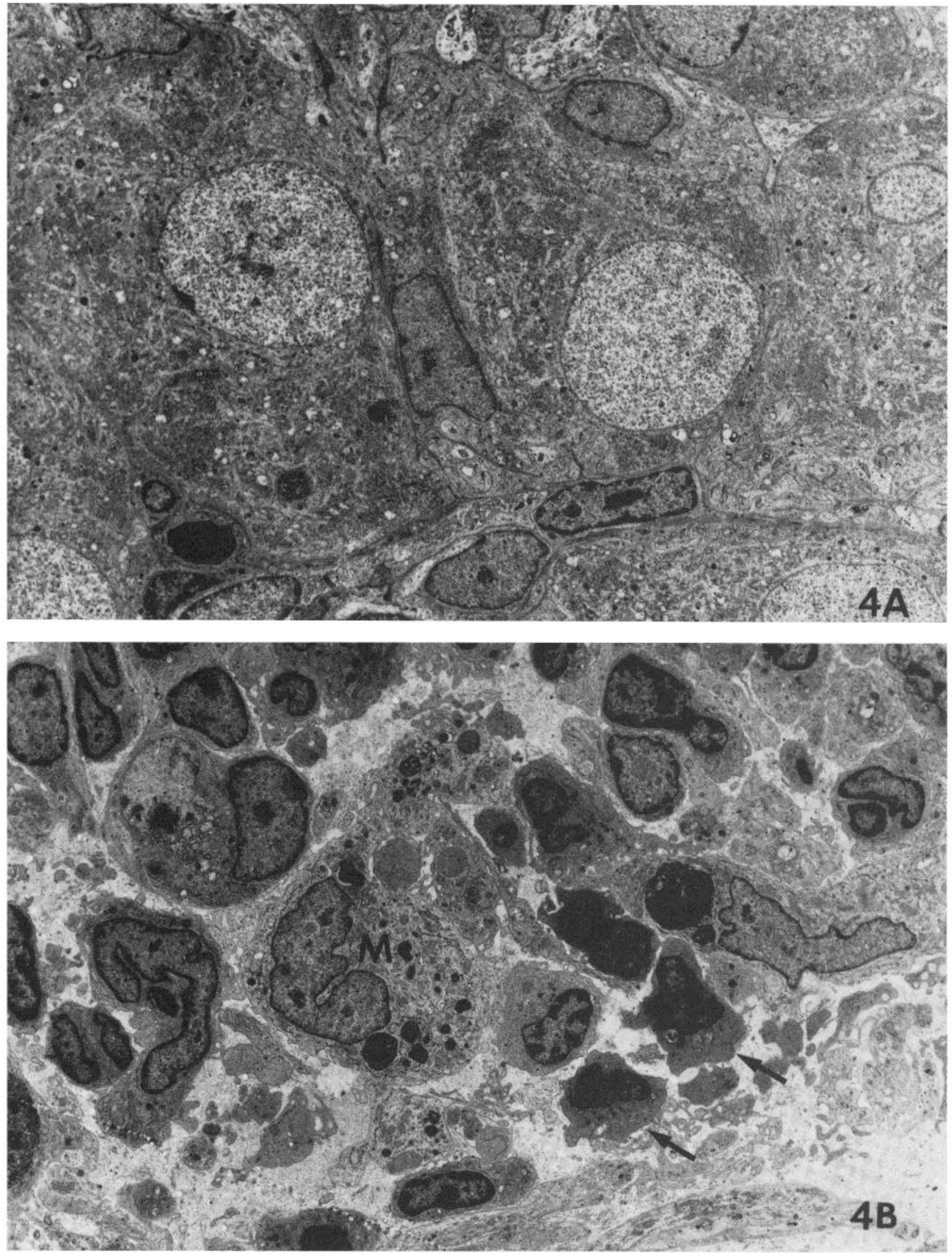

Figure 4. Effect of guanethidine on the ultrastructure of neonatal rat superior cervical ganglion. Superior cervical ganglia were examined in 14-day-old rat pups 7 days after daily administration of guanethidine as described under "Materials and Methods." $A$, Untreated neonatal superior cervical ganglion containing a complement of normal neurons $(\times 4700)$. $B$, Guanethidine-treated neonatal ganglion demonstrating widespread neuron loss, debris-laden macrophages $(M)$, and numerous infiltrating mononuclear cells (arrows) $(\times 3500)$.

guanethidine within the sympathetic neuron (Manning et al., 1982). In addition, we report here that the cellular infiltrate within the ganglia of guanethidine-treated rats consists of small lymphocytes as well as larger cells, which we interpreted to be activated lymphocytes. T lymphocytes, responsible largely for cell-mediated immune responses, were identified immunohistochemically within ganglia from treated animals. The presence of plasmacytoid cells suggests the possibility of participation of secreted immunoglobulins as well as a cell-me- 

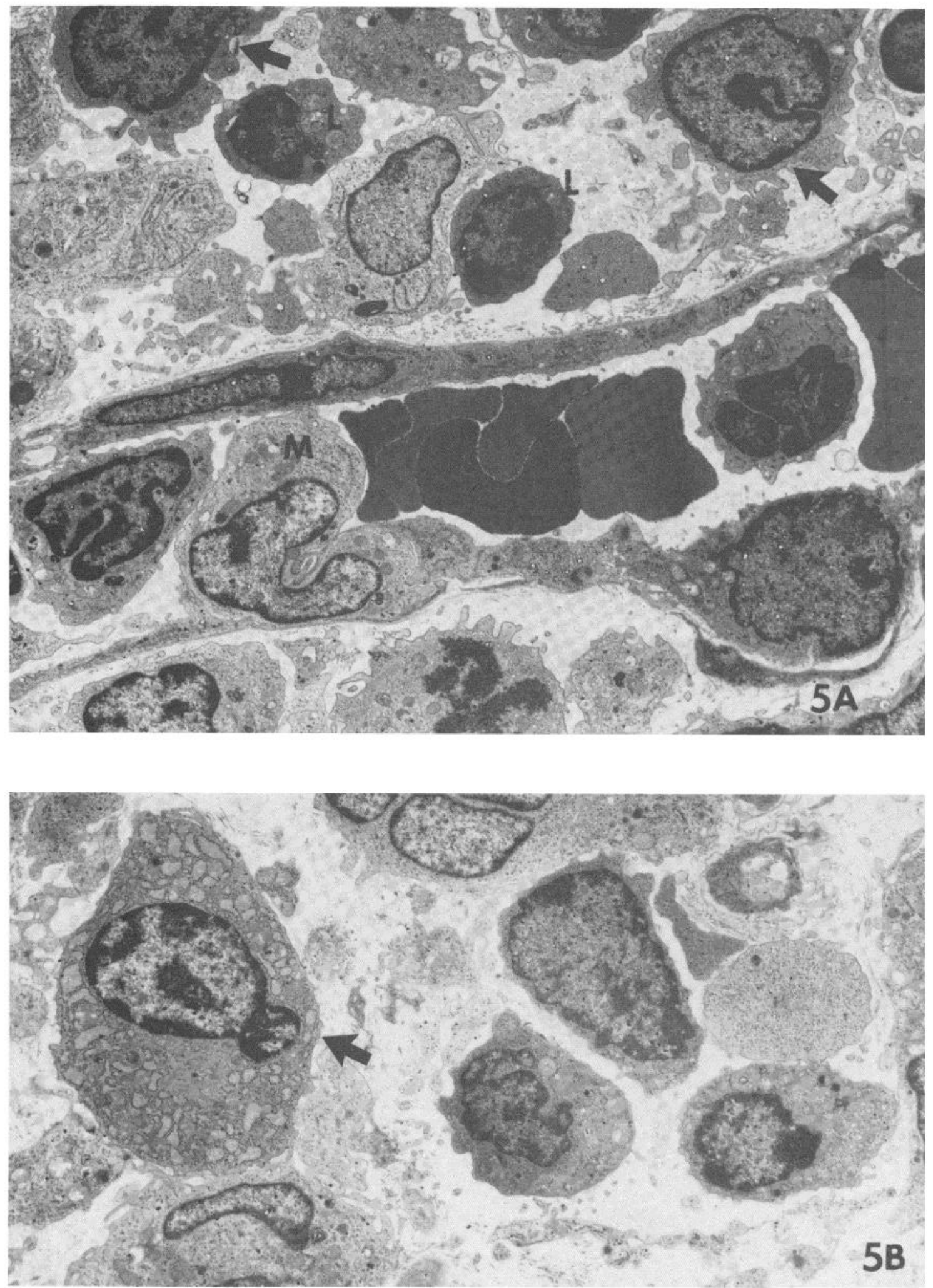

Figure 5. Ultrastructural characterization of the inflammatory infiltrate in guanethidine-treated neonatal rat superior cervical ganglion. The inflammatory cell infiltrate of guanethidine-treated ganglia presented in Figure 4 were examined at higher magnification. A, A pericapillary mononuclear cell infiltrate consists of several small lymphocytes $(L)$ as well as larger cells (arrows) with irregular, indented nuclei, a more delicate chromatin pattern, and increased amounts of dense cytoplasm, probably representing activated lymphocytes. A mononuclear cell $(M)$, probably a monocyte, is located between two endothelial cells. A mitotic figure is seen at the lower margin of the micrograph $(\times 4100)$. $B$, A group of inflammatory cells within the ganglionic interstitium consists of small lymphocytes as well as a plasmacytoid cell (arrow) containing large amounts of dilated endoplasmic reticulum $(\times 5100)$. 
diated mechanism in the immune response. The fact that guanethidine, in concentrations up to approximately 100 $\mu \mathrm{M}$, does not cause any observable changes in vitro of either explants of sympathetic neurons (Eränkö et al., 1972 ) or cultures of dissociated sympathetic neurons ( $P$. T. Manning and E. M. Johnson, unpublished data) further supports the role of an immune-mediated mechanism (immune competent cells are not present) and argues against a direct cytotoxic effect of guanethidine. This concentration of guanethidine has been calculated to be well in excess of that to which the sympathetic neuron would be exposed in vivo (Schanker and Morrison, 1965). Indeed, only concentrations of guanethidine at or above $200 \mu \mathrm{M}$ have been shown to produce axon retraction in vitro (Hill et al., 1973).

The immune reconstitution experiments demonstrate that the small cell infiltration and neuronal destruction due to guanethidine treatment require immune competency. Animals that were lethally irradiated could no longer mount an immune response after guanethidine treatment but regained sensitivity to guanethidine following transfer of immune competent cells. However, the magnitude of the decline in TOH activity as well as the severity of the histological changes, particularly the degree of small cell infiltration, were greater in intact than in immune reconstituted animals following guanethidine treatment. Although the number of cells transferred in experiment II was increased by 2.6 -fold, the reduction in TOH activity and the severity of degenerative changes were comparable to those in experiment I. One plausible explanation for the lack of a dose response relationship may involve the $\mathrm{Ia}^{+}$presenting cell of the recipient. Cells of macrophage lineage bearing Ia surface markers appear to be crucial in the regulation of $\mathrm{T}$ cell-mediated reactions. These cells somehow present antigens to the $T$ lymphocyte and initiate the immune induction process (Schwartz et al., 1978; Unanue, 1978). $\mathrm{Ia}^{+}$cells are radiosensitive (Beller and Unanue, 1981), and thus the number of antigen-presenting cells in the lethally irradiated recipients is probably significantly reduced. Bone marrow cells contain the precursors to $\mathrm{Ia}^{+}$antigen-presenting cells. However, even when transferring bone marrow cells, the number of cells which bear the $\mathrm{Ia}^{+}$surface marker has been shown not to be restored to normal levels in the irradiated recipient (Scher et al., 1982). Thus, the magnitude of the response following guanethidine treatment which is dependent upon presentation of the antigen to $\mathrm{T}$ lymphocytes may be diminished as compared to that which occurs in the intact animal. The precise immune mechanism responsible for the neuronal destruction remains to be elucidated; it may involve delayed-type hypersensitivity, cytotoxic $\mathrm{T}$ cells, antibody-dependent cell-mediated cytotoxicity, or any combination of the above.

Guanethidine-induced neuronal destruction which involves a drug-induced, apparently cell-mediated, autoimmune attack on the sympathetic neuron is perhaps a unique phenomenon. To our knowledge, the only other phenomenon which has been described in the literature that is similar is low dose streptozotocin-induced diabetes In this model, the $\beta$ cell of the pancreas is destroyed by a cell-mediated immune response resulting in insulitis and pronounced hyperglycemia (Like and Rossini, 1976; Rossini et al., 1977). A striking species specificity exists for both the streptozotocin (SZ) and guanethidine models. Only the rat is sensitive to the effects of guanethidine (Eränkö and Eränkö, 1971; O’Donnell and Saar, 1974; Johnson et al., 1977), certain strains exhibiting a greater sensitivity than others (P. T. Manning and E. M. Johnson, unpublished data). Similarly, only the outbred CD-1 and the inbred C57BL/KsJ mice respond with both insulitis and hyperglycemia following low dose SZ treatment (Leiter, 1982). As an experimental model of autoimmune diseases, guanethidine-induced neuronal destruction offers several distinct advantages over SZinduced destruction of the $\beta$ cell. The guanethidinetreated animal is not debilitated nor is its survival reduced. In addition, SZ is itself capable of destroying the $\beta$ cell by a direct toxic effect (Rakieten et al., 1963). In a variety of species guanethidine does not seem capable of destroying neurons in vivo by a direct toxic mechanism. Therefore, the role of toxicity versus immune-mediated destruction is not as clearly defined in SZ-induced diabetes as it is with guanethidine-induced neuronal destruction. SZ-induced diabetes is not known to be modified by hormone-like substances which act on the $\beta$ cell. In contrast and of considerable interest is the fact that nerve growth factor (which is necessary for survival and maintenance of sympathetic neurons both in vivo and in vitro) prevents guanethidine-induced neuronal cell death (Johnson and Aloe, 1974). The mechanism by which NGF prevents this response (possibly by preventing the expression of the guanethidine-induced antigen, blocking proliferation on the immune response, or blocking effector function) may provide insight into how NGF exerts its trophic effects.

\section{References}

Abramson, S., R. G. Miller, and R. A. Phillips (1977) The identification in adult bone marrow of pluripotent and restricted stem cells of the myeloid and lymphoid systems. J. Exp. Med. 145: 1567-1579.

Adams, J. C. (1981) Heavy metal intensification of DAB-based HRP reaction. J. Histochem. Cytochem. 29: 775.

Angeletti, P. U., and R. Levi-Montalcini (1970) Sympathetic nerve cell destruction in newborn mammals by 6 -hydroxydopamine. Proc. Natl. Acad. Sci. U. S. A. 65: 114-121.

Beller, D. I., and E. R. Unanue (1981) Regulations of macrophage populations. II. Synthesis and expression of Ia antigens by peritoneal exudate macrophages is a transient event. $\mathrm{J}$. Immunol. 126: '264-269.

Bukovsky, A., J. Presl, M. Holub, P. Mancal, and Z. Krabec (1982) Immunofluorescence study of the antibodies against rat thymocyte thy-1 antigen on the rat and mouse lymphatic tissue, brain, and kidney glomeruli. IRCS Med. Sci. 10: 6566.

Burnstock, G., B. Evans, B. J. Gannon, J. W. Heath, and V. James (1971) A new method of destroying adrenergic nerves in adult animals using guanethidine. Br. J. Pharmacol. 43: $295-301$.

Eränkö, L., and O. Eränkö (1971) Effect of guanethidine on nerve cells and small intensely fluorescent cells in sympathetic ganglia of newborn and adult rats. Acta Pharmacol. Toxicol. 30: 403-416.

Eränkö, L., C. Hill, O. Eränkö, and G. Burnstock (1972) Lack of toxic effects of guanethidine on nerve cells and small intensely 
fluorescent cells in cultures of sympathetic ganglia of newborn rats. Brain Res. 43: 501-513.

Ertl, H. C. J. (1981) Adoptive transfer of delayed-type hypersensitivity to Sendai virus. I. Induction of two different subsets of T lymphocytes which differ in $\mathrm{H}-2$ restriction as well as in the Lyt phenotype. Cell. Immunol. 62: 38-49.

Evans, B. K., G. Singer, S. Armstrong, P. E. Saunders, and G. Burnstock (1975) Effects of chronic intracranial injection of low and high concentrations of guanethidine in the rat. Pharmacol. Biochem. Behav. 3: 219-228.

Ford, W. L. (1978) The preparation and labelling of lymphocytes. In Hundbook of Experimental Immunology, D. M. Weir, ed., pp. 23.7-23.8, Blackwell, Oxford.

Heath, J. W., B. K. Evans, B. J. Gannon, G. Burnstock, and V. B. James (1972) Degeneration of adrenergic neurons following guanethidine treatment: An ultrastructural study. Virchows Arch. [Cell Pathol.] 11: 182-197.

Hill, C. E., G. E. Mark, O. Eränkö, L. Eränkö, and G. Burnstock (1973) Use of tissue culture to examine the actions of guanethidine and 6-hydroxydopamine. Eur. J. Pharmacol. 23: 162-174.

Ishii, Y., H. Koshiba, H. Ueno, I. Maeyama, T. Takami, F. Ishibashi, and K. Kikuchi (1975) Characterization of human B lymphocyte specific antigens. J. Immunol. 114: 466-469.

Jensen-Holm, J., and P. Juul (1971) Ultrastructural changes in the rat superior cervical ganglion following prolonged guanethidine administration. Acta Pharmacol. Toxicol. 30: 308320 .

Johnson, E. M. (1978) Destruction of the sympathetic nervous system in neonatal rats and hamsters by vinblastine: Prevention by concomitant administration of nerve growth factor. Brain Res. 141: 105-118.

Johnson, E. M., and L. Aloe (1974) Suppression of the in vitro and in vivo cytotoxic effects of guanethidine in sympathetic neurons by nerve growth factor. Brain Res. 81: 519-532.

Johnson, E. M., and F. E. Hunter (1979) Chemical sympathectomy by guanidinium adrenergic neuron blocking agents. Biochem. Pharmacol. 28: 1525-1531.

Johnson, E. M., and A. S. Taylor (1980) Inhibition of S-adenosyl methionine decarboxylase by guanethidine. Biochem. Pharmacol. 29: 113-115.

Johnson, E. M., R. A. Macia, and T. O. Yellin (1977) Marked difference in the susceptibility of several species to guanethidine-induced chemical sympathectomy. Life Sci. 20: 107112.

Johnson, E. M., R. A. Macia, R. Y. Andres, and R. Bradshaw (1979) The effects of drugs which destroy the sympathetic nervous system on the retrograde transport of nerve growth factor. Brain Res. 171: 461-472.

Julius, M. H., E. Simpson, and L. A. Herzenberg (1973) $\Lambda$ rapid method for the isolation of functional thymus-derived murine lymphocytes. Eur. J. Immunol. 3: 645-649.

Juul, P., and O. Sand (1973) Determination of guanethidine in sympathetic ganglia. Acta Pharmacol. Toxicol. 2: 487-499.

Kaplan, M. H. (1958) Localization of streptococcal antigens in tissues. J. Exp. Med. 107: 341-352.

Kohn, H. I. (1951) Effects of X-rays upon hemolysin production in the rat. J. Immunol. 66: 525-533.

Leiter, E. H. (1982) Multiple low-dose streptozotocin-induced hyperglycemia and insulitis in C57BL mice: Influence of inbred background, sex, and thymus. Proc. Natl. Acad. Sci. IJ. S. A. 79: 630-634.

Levi-Montalcini, R., and P. U. Angeletti (1966) Immunosympathectomy. Pharmacol. Rev. 18: 619-628.

Like, A. A., and A. A. Rossini (1976) Streptozotocin-induced pancreatic insulitis: New model of diabetes mellitus. Science 193: 415-417.

Manning, P. T., J. H. Russell, and E. M. Johnson (1982) Immunosuppressive agents prevent guanethidine-induced destruction of rat sympathetic neurons. Brain Res. 241: 131143.

Nagatsu, T., M. Levitt, and S. Undenfriend (1964) Tyrosine hydroxylase: The initial step in norepinephrine biosynthesis. J. Biol. Chem. 239: 2910-2917.

O'Donnell, S. R., and N. Saar (1974) The effects of 6-hydroxydopamine and guanethidine on peripheral adrenergic nerves in the guinea pig. Eur. J. Pharmacol. 28: 251-256.

Paterson, P. Y. (1960) Transfer of allergic encephalomyelitis in rats by means of lymph node cells. J. Exp. Med. 111: 119136.

Rakieten, N., M. L. Rakieten, and M. R. Nadkarni (1963) Studies on the diabetogenic action of streptozotocin (NSC37917). Cancer Chemother. Kep. 29: 91-98.

Révész, E., and E. van der Zypen (1979) Ultrastructural changes in adrenergic neurons following chemical sympathectomy. Acta Anat. 105: 198-208.

Rossini, A. A., A. A. Like, W. L. Chick, M. C. Appel, and G. F. Cahill, Jr. (1977) Studies of streptozotocin-induced insulitis and diabetes. Proc. Natl. Acad. Sci. U. S. A. 74: 2485-2489.

Schanker, L. S., and A. S. Morrison (1965) Physiological disposition of guanethidine in the rat and its uptake by heart slices. Int. J. Neuropharmacol. 4: 27-39.

Scher, M. G., E. R. Unanue, and D. I. Beller (1982) Regulation of macrophage populations. III. The immunologic induction of exudates rich in Ia-bearing macrophages in a radiosensitive process. J. Immunol. 128: 447-450.

Schwartz, R. H., A. Yano, and W. E. Paul (1978) Interaction between antigen-presenting cells and primed $\mathrm{T}$ lymphocytes. Immunol. Rev. 40: 153-180.

Uede, T., Y. Ishii, A. Matsuura, I. Shimogawara, and K. Kikuchi (1981) Immunohistochemical study of lymphocytes in rat pineal gland: Selective accumulation of T lymphocytes. Anat. Rec. 199: 239-247.

Unanue, E. R. (1978) The regulation of lymphocyte functions by the macrophage. Immunol. Rev. 40: 227-255. 